\title{
Association between measures of insulin sensitivity and circulating levels of interleukin-8, interleukin-6 and tumor necrosis factor- $\alpha$. Effect of weight loss in obese men
}

\author{
Jens M Bruun, Camilla Verdich ${ }^{1}$, Søren Toubro ${ }^{1}$, Arne Astrup ${ }^{1}$ and Bjørn Richelsen \\ Department of Endocrinology and Metabolism C, Aarhus Amtssygehus, Aarhus University Hospital and Faculty of Health Sciences, \\ Aarhus University, DK-8000 Aarhus C, Denmark and ${ }^{1}$ Research Department of Human Nutrition, Centre for Advanced Food Research, \\ The Royal Veterinary and Agricultural University, DK-1958 Frederiksberg C, Denmark
}

(Correspondence should be addressed to J M Bruun, Department of Endocrinology and Metabolism, Aarhus Amtssygehus, Tage Hansensgade 2, DK-8000 Aarhus C, Denmark; Email: jmb@mail-online.dk)

\begin{abstract}
Objective: To study the association between anthropometric and metabolic parameters as well as the effect of weight loss on plasma levels of the adipose tissue-derived cytokines interleukin-8 (IL-8), interleukin-6 (IL-6) and tumor necrosis factor- $\alpha$ (TNF- $\alpha$ ) in abdominal obese men.

Subjects: Nineteen obese (mean body mass index (BMI): $38.6 \pm 0.6 \mathrm{~kg} / \mathrm{m}^{2}$ ) and ten lean men (mean BMI: $23.4 \pm 0.4 \mathrm{~kg} / \mathrm{m}^{2}$ ) were included in the study. The obese subjects received a $4.2 \mathrm{MJ} /$ day diet for 8 weeks, followed by 8 weeks on energy restriction (6.2 MJ/day) and 8 weeks on a weight-maintenance diet.

Measurements: A dual energy X-ray absorptiometry (DEXA)-scan was performed to estimate body composition. Plasma levels of IL-8, IL- 6 and TNF- $\alpha$ were measured by a specific ELISA method. Insulin sensitivity was assessed by the homeostasis model assessment method (HOMA).

Results: Plasma levels of IL-8 and IL-6 were 30-40\% higher in obese as compared with lean subjects $(P<0.05)$, whereas no group difference in TNF- $\alpha$ was observed. During the intervention, obese subjects obtained a $30 \%$ reduction in fat mass $(P<0.001)$, fasting insulin $(P<0.05)$ and HOMA $(P<0.05)$. Plasma levels of TNF- $\alpha$ and IL-6 were decreased by $25-30 \%(P<0.001)$ but IL- 8 was increased by 30\% $(P<0.001)$ after weight loss. IL-8 and IL-6 were correlated with measures of insulin resistance, and changes in IL- 6 but not IL- 8 were correlated with the improvement in insulin sensitivity after weight loss.

Conclusion: Plasma levels of IL- 8 and IL- 6 were found to be increased and were correlated with measures of insulin resistance in abdominal obese male subjects. Weight loss was associated with changes in the circulating levels of IL-8, IL-6 and TNF- $\alpha$ indicating that these cytokines are influenced by weight loss.
\end{abstract}

European Journal of Endocrinology 148 535-542

\section{Introduction}

The link between obesity and the increased risk of developing insulin resistance, type 2 diabetes and cardiovascular disease have still not been fully elucidated (1-3). However, during the last decade it has become increasingly clear that the adipose tissue itself produces and releases a number of cytokines and hormone-like proteins such as interleukin-6 (IL-6) (4), tumor necrosis factor- $\alpha$ (TNF- $\alpha$ ) (5), interleukin-8 (IL-8) (6), leptin (7), plasminogen activator inhibitor-1 (8) and adiponectin (9), all of which may be of importance for this association between obesity and health complications. Although the majority of these cytokines and hormone-like proteins are produced and released not solely from the adipocytes, protein levels of cytokines such as IL- 6 and TNF- $\alpha$ are found to be elevated in plasma as well as in the adipose tissue of obese subjects $(10,11)$, and weight loss is associated with changes in these adipose tissue-derived cytokines $(10,11)$.

TNF- $\alpha$ has been found to induce metabolic changes in insulin action, glucose transport and lipid metabolism especially in animal models, mimicking the insulin resistance and metabolic changes found in patients with type 2 diabetes (12-14). In addition, 
TNF- $\alpha$ is known to stimulate the production of other cytokines such as IL-8 and IL- $6(6,15)$, and has been demonstrated to be associated with obesity and insulin resistance (16). However, not all studies are compatible with the suggestion that TNF- $\alpha$ is of importance for the obesity-associated insulin resistance in humans (17).

IL- 6 is produced and released from human adipose tissue (18), and circulating levels of IL-6 are found to be increased with increasing adiposity and are associated with the development of obesity-related health complications such as insulin resistance and cardiovascular disease $(16,19,20)$. When measuring the arterio-venous difference of IL- 6 and TNF- $\alpha$ over the abdominal subcutaneous adipose tissue depot in the basal (non stimulated) situation, IL- 6 but not TNF- $\alpha$ is found to be released into the circulation (4). This suggests that adipose tissue-derived IL- 6 is released into the circulation in a sufficient concentration to elicit endocrine effects (4).

It has recently been demonstrated by our group (6) as well as by Gerhardt and coworkers (21) that IL-8 is produced and released from human mature isolated adipocytes as well as from cultured human adipose tissue fragments in a regulated manner. IL-8 has, besides its association with a number of inflammatory processes, recently been implicated in the pathogenesis of atherosclerosis $(22-25)$. In addition, it has been reported that serum levels as well as urinary levels of IL-8 were significantly increased in patients with type 2 diabetes with and without nephropathy $(26,27)$.

Since IL-8, IL- 6 and TNF- $\alpha$ are found to be highly expressed and released from human adipose tissue and no one, to our knowledge, has made parallel investigations on these three cytokines, we investigated, in the present study, the possible association between weight loss, insulin sensitivity and changes in the circulating levels of IL-8, IL-6 and TNF- $\alpha$ in 19 abdominal obese men in order to obtain more information on the possible role of these cytokines in the obese state.

\section{Subjects and methods}

\section{Subjects}

Twenty-nine healthy male subjects were included in the study (range: 18-48 years). Nineteen abdominal obese men with a mean body mass index (BMI) of $38.6 \pm 0.6 \mathrm{~kg} / \mathrm{m}^{2}$ (range: $34.1-43.8 \mathrm{~kg} / \mathrm{m}^{2}$ ) were compared at baseline with ten lean men with a mean BMI of $23.4 \pm 0.4 \mathrm{~kg} / \mathrm{m}^{2}$ (range: $21.1-24.7 \mathrm{~kg} / \mathrm{m}^{2}$ ). The two groups were matched for age (mean age: lean $34.9 \pm 2.6$ years and obese $35.0 \pm 2.3$ years) and height (Table 1). All subjects were Caucasian, non-diabetic and none of them used any medication. The obese subjects were controlled for weight stability every second week throughout a run-in period of 6 weeks.

The intervention study consisted of three parts. First, the obese subjects received a controlled 4.2 MJ/day, low calorie diet for 8 weeks (GERLINÉA; WASABRØD A/S; Skovlunde, Denmark) with five daily meals consisting of $30 \mathrm{~g}$ nutrition powder suspended in $200 \mathrm{ml}$ skimmed milk providing $77.5 \mathrm{~g}$ protein, $102 \mathrm{~g}$ carbohydrate and $30 \mathrm{~g}$ fat. This was followed by 8 weeks on energy restriction providing $6.2 \mathrm{MJ} /$ day and an additional 8 weeks on a calculated weight-maintenance diet as previously described (28).

Both lean and obese subjects arrived at the department at approximately $0800 \mathrm{~h}$, without having performed any kind of exercise prior to the visit. Fasting blood samples were obtained from the antecubital vein at baseline and at the end of the study, after 24 weeks. Fasting body weight was measured to the nearest $0.1 \mathrm{~kg}$ by a Lindeltronic 8000 scale (Copenhagen, Denmark) at baseline and after 24 weeks. Measurements of waist circumference were performed by the same

Table 1 Clinical characteristics of the patients. Baseline characteristics of the 19 obese men (BMI range: $\left.34.1-43.8 \mathrm{~kg} / \mathrm{m}^{2}\right)$ and ten lean men (BMI range: $21.1-24.7 \mathrm{~kg} / \mathrm{m}^{2}$ ) included in the study, as well as characteristics of the 19 obese after weight loss (at week 24 ). Data represent mean values \pm S.E.M.

\begin{tabular}{|c|c|c|c|}
\hline & \multicolumn{2}{|c|}{ Baseline } & \multirow[b]{2}{*}{ Week 24 reduced obese } \\
\hline & Lean & Obese & \\
\hline Body weight (kg) & $75.7 \pm 1.8$ & $127.6 \pm 3.2^{\star \star \star}$ & $108.9 \pm 3.8^{\# \# \#}$ \\
\hline Height $(\mathrm{cm})$ & $180 \pm 2.1$ & $181.5 \pm 1.8^{\mathrm{NS}}$ & $181.5 \pm 1.8^{\mathrm{NS}}$ \\
\hline BMI $\left(\mathrm{kg} / \mathrm{m}^{2}\right)$ & $23.4 \pm 0.4$ & $38.7 \pm 0.7^{\star \star * *}$ & $33.0 \pm 1.0^{\# \# \#}$ \\
\hline Fat mass $(\mathrm{kg})$ & $14.4 \pm 1.7$ & $50.3 \pm 2.3^{\star \star \star}$ & $35.5 \pm 3.0^{\# \# \#}$ \\
\hline Trunk fat mass (kg) & $3.2 \pm 0.6$ & $21.5 \pm 1.2^{\star \star \star}$ & $12.4 \pm 1.6^{\# \# \#}$ \\
\hline Waist $(\mathrm{cm})$ & $83.1 \pm 1.2$ & $124.9 \pm 1.9^{\star \star \star}$ & $105.6 \pm 2.8^{\# \# \#}$ \\
\hline Insulin (pM) & $33.8 \pm 3.5$ & $110.2 \pm 11.1^{\star \star \star}$ & $77.9 \pm 15.8^{\#}$ \\
\hline Glucose (mM) & $4.9 \pm 0.1$ & $5.3 \pm 0.1^{*}$ & $5.0 \pm 0.1^{\mathrm{NS}}$ \\
\hline HOMA & $7.1 \pm 0.8$ & $26.0 \pm 2.9 * \star \star$ & $14.5 \pm 2.1^{\# \# \#}$ \\
\hline IL-8 (pg/ml) & $3.2 \pm 0.5$ & $4.4 \pm 0.3^{\star}$ & $5.7 \pm 0.3^{\# \# \#}$ \\
\hline IL-6 (pg/ml) & $2.5 \pm 0.6$ & $4.1 \pm 0.4^{*}$ & $3.1 \pm 0.4^{\# \# \#}$ \\
\hline TNF- $\alpha(\mathrm{pg} / \mathrm{ml})$ & $4.6 \pm 0.5$ & $4.8 \pm 0.5^{\mathrm{NS}}$ & $3.4 \pm 0.4^{\# \# \#}$ \\
\hline
\end{tabular}

${ }^{\star} P<0.05,{ }^{\star \star \star} P<0.001$ lean vs obese (unpaired $t$-test); ${ }^{\#} P<0.05,{ }^{\# \# \#} P<0.001$ obese baseline vs obese week 24 (paired $t$-test). ${ }^{\text {NS }}$ Not significant. 
person at the time-points indicated. Body composition was assessed by dual energy X-ray absorptiometry (DEXA)-scan at baseline and again at the end of the study, but at this time-point only obese subjects were investigated. Assessment of individual body composition was carried out using a Lunar DPX-IQ Image Densiometer (DPX, Lunar Radiation Corporation; Madison, WI, USA). All DEXA-scans were performed in the morning on fasting subjects, as previously described (29).

\section{Laboratory analysis}

Plasma was separated and frozen at $-20^{\circ} \mathrm{C}$ until the time of the assay. Plasma samples for determination of fasting insulin and fasting glucose were analyzed at the local clinical biochemical laboratory and measures for insulin resistance were obtained using the homeostasis model assessment (HOMA = fasting insulin* fasting glucose/22.5) (30).

\section{IL-8, IL-6 and TNF- $\alpha$ protein measurements}

The IL- 8 , IL- 6 and TNF- $\alpha$ protein levels were measured in plasma samples using a specific human enzymelinked immunosorbent assay (ELISA) method. The following assays were used: IL-8 Quantiglo (R\&D Systems Europe Ltd, Barton Lane, Abingdon, UK) with an intraassay coefficient of variation of $6.4 \%(n=12)$ and an interassay coefficient of variation of $7.9(n=6)$, IL-6 Quantiglo (R\&D Systems Europe Ltd) with an intraassay coefficient of variation of $5.5 \%(n=12)$ and an interassay coefficient of variation of $12.7 \% \quad(n=7)$ and TNF- $\alpha$ Quantiglo (R\&D Systems Europe Ltd) with an intra-assay coefficient of variation of $3.5 \%$ $(n=20)$ and an interassay coefficient of variation of $9.0 \%(n=40)$.

\section{Statistical analysis}

The values are presented as mean \pm s.E.M. The SPSS statistical package (SPSS/8.0, SPSS, Chicago, IL, USA) was used for the calculations. For comparison between anthropometrical data, body composition, various parameters of insulin sensitivity and plasma levels of IL-8, IL- 6 or TNF- $\alpha$ in obese subjects before and after weight loss a paired Student's $t$-test was used. For comparison between plasma levels of IL- 8 , IL- 6 or TNF- $\alpha$, anthropometrical data, body composition and various parameters of insulin sensitivity in lean and obese subjects an independent Student's t-test was used. To determine the relationship between the various metabolic and anthropometrical parameters and plasma levels of IL-8, IL- 6 and TNF- $\alpha$ at baseline as well as after weight loss bivariate correlations with a Pearson correlation coefficient $\left(r_{p}\right)$ were used. The threshold for significance was set at $P<0.05$.

\section{Ethics}

Informed, written consent was obtained from all subjects after the study protocol had been described to them in writing and orally. The study was approved by the Ethical Committees of Copenhagen, Frederiksberg and Zealand in accordance with the Helsinki II Declaration.

\section{Results}

\section{Cytokines, anthropometric and metabolic parameters at baseline}

As shown in Table 1, obese subjects compared with lean subjects were found to have significantly higher amounts of total body fat as well as more visceral adipose tissue as estimated by trunk fat mass and waist circumference. In addition, obese subjects were found to be more insulin resistant than lean controls as assessed by fasting insulin and HOMA $(P<0.001)$.

Plasma levels of IL-8 and IL-6 were found to be $38 \%$ $(P<0.05)$ and 64\% $(P<0.05)$ higher in obese as compared with lean subjects (Table 1 and Fig. 1). In contrast, no difference was observed in the plasma levels of TNF- $\alpha$ between the two groups (Table 1 and Fig. 1).

When looking at lean subjects separately no association was found between IL- 8 , IL- 6 or TNF- $\alpha$ and a number of anthropometric and metabolic parameters (data not shown). In obese subjects, IL-8 was not found to be associated with anthropometric parameters related to adiposity or to visceral adiposity (Table 2). IL-8 was correlated with fasting insulin levels $(P<0.05)$ but only marginally with HOMA $(P=0.05)$ (Table 2 and Fig. 2). Plasma levels of IL-6

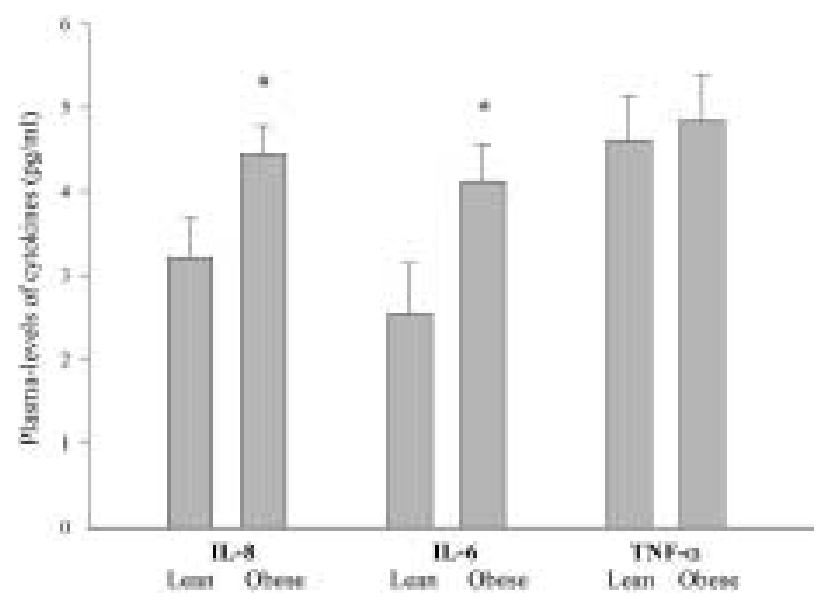

Figure 1 Difference in the circulating levels of IL-8, IL- 6 or TNF- $\alpha$ in plasma samples obtained from ten lean and 19 obese individuals. Protein levels of IL-8, IL- 6 and TNF- $\alpha$ were measured by ELISA as described in the Subjects and methods section. ${ }^{\star} P<0.05$ compared with plasma levels in lean subjects. 
Table 2 Association between plasma levels of cytokines and metabolic and anthropometric parameters at baseline in 19 obese men (BMI range: $34.1-43.8 \mathrm{~kg} / \mathrm{m}^{2}$ ).

\begin{tabular}{llll}
\hline & \multicolumn{1}{c}{ IL-8 } & \multicolumn{1}{c}{ IL-6 } & \multicolumn{1}{c}{ TNF- $\boldsymbol{\alpha}$} \\
\hline BMI $\left(\mathrm{kg} / \mathrm{m}^{2}\right)$ & $0.32^{\mathrm{NS}}$ & $0.30^{\mathrm{NS}}$ & $0.18^{\mathrm{NS}}$ \\
Fat mass $(\mathrm{kg})$ & $0.40(P=0.09)$ & $0.29^{\mathrm{NS}}$ & $0.23^{\mathrm{NS}}$ \\
Waist $(\mathrm{cm})$ & $0.39(P=0.10)$ & $0.34^{\mathrm{NS}}$ & $0.11^{\mathrm{NS}}$ \\
Insulin $(\mathrm{pM})$ & $0.47^{*}$ & $0.54^{*}$ & $0.45(P=0.05)$ \\
HOMA & $0.45(P=0.05)$ & $0.57^{\star *}$ & $0.43(P=0.07)$ \\
\hline
\end{tabular}

${ }^{\star} P<0.05, \quad{ }^{*} P<0.01$ and ${ }^{\mathrm{NS}}$ not significant (bivariate correlation with Pearson correlation coefficient).

were found to be correlated with HOMA $(P<0.01)$ and fasting insulin $(P<0.05)$ (Fig. 2), but not with any of the anthropometric parameters (Table 2). No association was found between plasma levels of TNF- $\alpha$ and the anthropometric and metabolic parameters investigated. However, measures of insulin sensitivity displayed a trend towards a negative association (Table 2 and Fig. 2). Of the three cytokines investigated, plasma levels of TNF- $\alpha$ were found to be correlated with plasma levels of IL-6 $\left(\mathrm{r}_{\mathrm{p}}=0.46 ; P<0.05\right)$ and IL-8 $\left(r_{p}=0.49 ; P<0.05\right)$. No association was found between plasma levels of IL-6 and IL-8 $\left(r_{p}=0.33\right.$; $P=0.09)$.

\section{Effects of weight loss on plasma levels of IL-8, IL-6 and TNF- $\alpha$}

After having received a restrictive diet for 24 weeks the obese subjects had reduced their body weight by $15 \%$ $(P<0.001)$, their total body fat mass by $30 \%(P<$ $0.001)$ and their waist circumference by approximately $20 \%(P<0.001)$ (Table 1). The decreases in both total fat mass and visceral fat mass were mirrored by a significant improvement in insulin sensitivity as demonstrated by a decrement in fasting insulin and HOMA (Table 1). The improvement in insulin sensitivity was paralleled by a reduction in circulating levels of IL- 6 by $25 \% \quad(4.1 \pm 0.4 \mathrm{pg} / \mathrm{ml}$ vs $3.1 \pm 0.4 \mathrm{pg} / \mathrm{ml}$; $P<0.001)$ and TNF- $\alpha$ by $30 \%(4.8 \pm 0.5 \mathrm{pg} / \mathrm{ml}$ vs $3.4 \pm 0.4 \mathrm{pg} / \mathrm{ml} ; \quad P<0.001$ ) (Table 1 and Fig. 3). Opposed to this, circulating levels of IL-8 were increased by $30 \%(4.4 \pm 0.3 \mathrm{pg} / \mathrm{ml}$ vs $5.7 \pm 0.3 \mathrm{pg} / \mathrm{ml}$; $P<0.001$ ) after weight loss (Table 1 and Fig. 3 ).

In obese subjects, the differences between baseline and final concentrations of IL- $8(\Delta \mathrm{IL}-8)$ and TNF- $\alpha$ $(\Delta \mathrm{TNF}-\alpha)$ were not found to be correlated with any of the changes in the anthropometric or metabolic parameters investigated (data not shown). However, the decrease in IL-6 ( $\Delta$ IL-6) observed after weight loss was correlated with the decrease in fasting insulin levels and the improvement in insulin sensitivity as assessed by HOMA (Fig. 4). No association was found between $\Delta \mathrm{IL}-6$ and $\Delta \mathrm{TNF}-\alpha\left(\mathrm{r}_{\mathrm{p}}=0.43 ; \mathrm{P}=0.07\right)$.

\section{Discussion}

It is well established that human adipose tissue has the capacity to produce and secrete a variety of proteins including cytokines (e.g. TNF- $\alpha$ (10) and IL-6 (11)) and chemokines (e.g. IL-8 (6) and monocyte chemoattractant and activating protein-1 (MCP-1) (21)), some of which might be involved in the development of obesity-related diseases through autocrine, paracrine or endocrine signaling $(4,31)$.

Previous weight loss studies have only investigated up to two adipose tissue-derived cytokines in parallel. In the present study, plasma levels of IL-8, IL- 6 and $\mathrm{TNF}-\alpha$ were assessed in parallel in ten lean and 19 obese men. In addition, the effect of a diet-induced weight loss on these cytokines in the obese men was investigated. IL- 8 and IL- 6 , but not TNF- $\alpha$ were found to be increased in obese subjects, and weight loss was associated with a decrement in the circulating levels of IL- 6 and TNF- $\alpha$, but an increment in IL- 8 . In obese subjects at baseline, IL- 8 and IL- 6 , but not TNF- $\alpha$, were found to be associated with measures of insulin sensitivity (fasting insulin and HOMA) and plasma levels of TNF- $\alpha$ were found to be correlated with IL-6 and IL-8. The decrease in IL- 6 observed after weight loss was correlated with the augmentation in insulin sensitivity as demonstrated by a decrement in fasting insulin and HOMA.

Even though the cytokines investigated are known to be released from mature human adipocytes, it is not known whether the changes observed in the circulating levels of IL- 8 , IL- 6 and TNF- $\alpha$ in the present study are due to secretory changes in the adipose tissue. However, reports have previously demonstrated that changes in the circulating protein levels of IL-8, IL-6 and TNF- $\alpha$ after weight loss were paralleled by changes in adipose tissue protein levels of IL-8 (32), IL-6 (11) and TNF- $\alpha$ (33), which indicates that circulating levels of the cytokines investigated may, to some extent, mirror changes in the adipose tissue. The results on IL-6 and measures of insulin sensitivity are in accordance with two recent studies $(16,34)$ further emphasizing that IL-6 may be of importance for the obesity-related insulin resistance. Although we recently found that weight loss induced an increase in plasma levels as well as adipose tissue levels of IL-8 (32), the new and interesting finding relating to IL-8 in this study is that circulating levels of IL-8 are increased in obese as compared with lean subjects and are associated with measures of insulin sensitivity at baseline. These new findings are of interest since chemokines such as IL- 8 and MCP-1 have been suggested to be involved in the pathogenesis of diseases associated with excess amounts of adipose tissue e.g. atherosclerosis and cardiovascular disease $(25,35)$. In addition, circulating levels of IL- 8 have been reported to be increased in patients with type 1 and type 2 diabetes (26) linking these chemokines with insulin resistance. 
However, in contrast to IL-6 and especially TNF- $\alpha$, no research has, to our knowledge, been conducted on the effects of IL-8 on cellular insulin sensitivity. If, as expected, weight loss is beneficial then the decrement in IL-6 and TNF- $\alpha$ after weight loss is understandable, but the increment in plasma levels of IL-8 is not.
One explanation could be that IL-8, besides its secretion from adipocytes, is also released from several cell types involved in acute as well as chronic inflammatory responses (36), often orchestrated by TNF- $\alpha$ (37). However, adipose tissue-derived TNF- $\alpha$ is suggested to elicit its effects in an autocrine or paracrine fashion
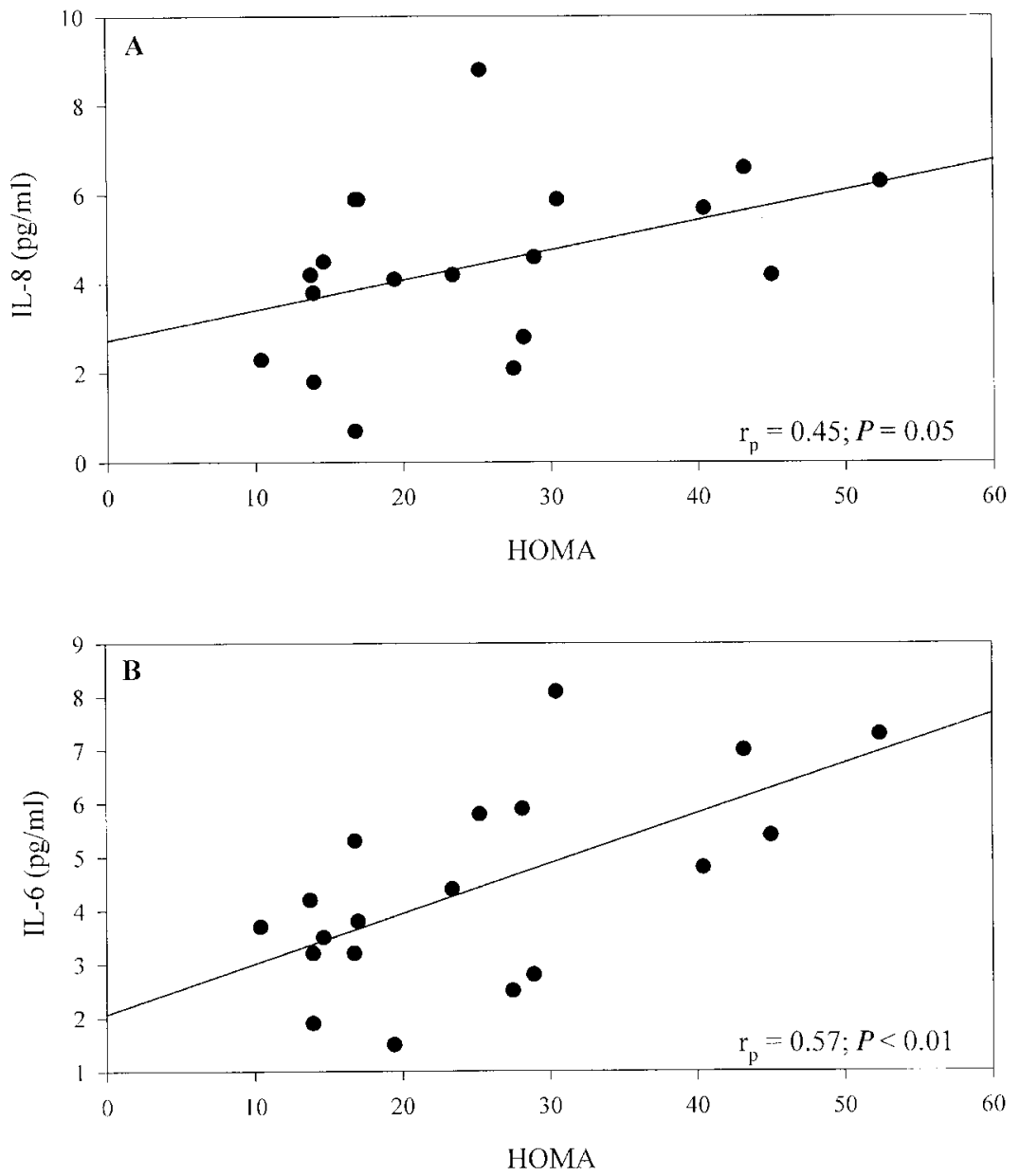

Figure 2 Correlation between HOMA and plasma levels of IL-8, IL-6 or TNF- $\alpha$. Measures of insulin sensitivity as assessed by HOMA were compared with the circulating levels of IL-8 (A), IL-6 (B) or TNF- $\alpha$ (C) in 19 obese men. HOMA was calculated as described in the Subjects and methods section. Bivariate correlation was assessed with Pearson correlation coefficient $\left(r_{p}\right)$. 


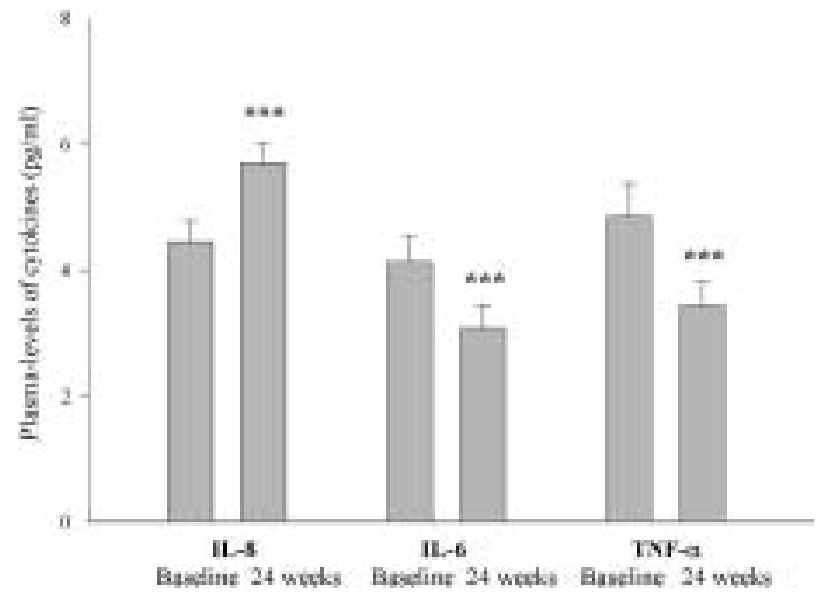

Figure 3 Effects of weight loss on plasma levels of IL-8, IL-6 and TNF- $\alpha$. Plasma levels of IL-8, IL-6 and TNF- $\alpha$ in 19 obese subjects were assessed before (baseline) and after weight loss ( 24 weeks). Protein levels of IL-8, IL- 6 and TNF- $\alpha$ were measured by ELISA as described in the Subjects and methods section. ${ }_{\star \star \star} P<0.001$ compared with plasma levels before weight loss.

(4) and none of the included patients was found to have any major inflammatory disease, even though obesity per se has been demonstrated to be associated with an increment in circulating levels of markers of inflammation such as C-reactive protein (CRP) $(11,38,39)$. However, some discrepancy still exists on the effect of weight loss, since not all studies have been able to report that weight loss was paralleled by a reduction in CRP $(11,39)$. Another explanation for the increment in circulating levels of IL-8 could therefore be the result of changes in inflammatory markers other than the cytokines investigated in the present study or could be due to weight loss-associated release of other substances from the adipose tissue, such as organochlorine compounds (40), that may stimulate the release of IL- 8 .

IL- 6 and TNF- $\alpha$ are also produced and released from human adipose tissue $(18,41)$, and the circulating levels have been found to be correlated with measures of obesity, insulin resistance and cardiovascular disease in many studies $(10,16,19,20$, $42)$ but not in all $(17,43)$. Another new finding in the present study was that plasma levels of TNF- $\alpha$ correlated with circulating levels of IL- 6 and IL-8, which supports the hypothesis that TNF- $\alpha$ is a leader cytokine inducing the production and release of other cytokines (e.g. IL-8 and IL-6) (37). Even though Bastard and coworkers (34) found no correlation between IL- 6 and TNF- $\alpha$, the findings in the present study could be of importance since in vitro studies have demonstrated that TNF- $\alpha$ can induce the production of IL- 8 and IL- 6 from adipose tissue $(6,44)$. After weight loss TNF- $\alpha$ was associated, although insignificantly, with IL- 6 but not with IL-8. The decrement in plasma levels of IL-6 after weight loss in obese men was correlated with an improvement in insulin sensitivity, which is in agreement with a study by Bastard and coworkers who have demonstrated a similar correlation between IL-6 and insulin sensitivity after weight loss in obese women (11). The decrease in plasma levels of TNF- $\alpha$ after weight loss are in accordance with reports by others $(10,33)$.

In conclusion, we demonstrated that circulating concentrations of IL-8 and IL- 6 were increased in obese men and were correlated with measures of insulin sensitivity (e.g. HOMA and fasting insulin) at baseline. Although large amounts of IL-8 are produced and released from human adipose tissue in vitro (6), it is presently unclear whether circulating levels of IL-8 are influenced by the IL- 8 released from the adipose tissue. One way to test this hypothesis would be to conduct investigations on the direct
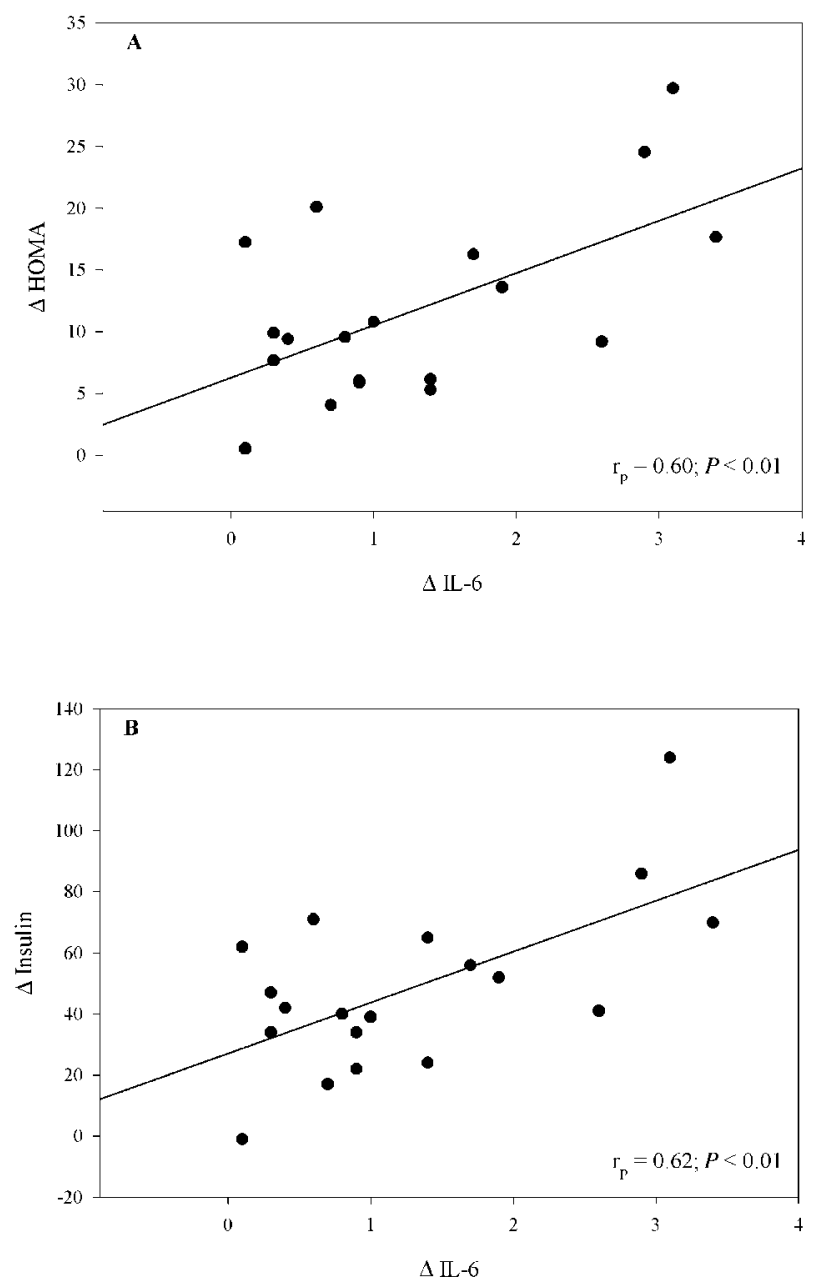

Figure 4 Correlation between the changes in plasma levels of IL-6 and HOMA or fasting insulin. The decrement in circulating levels of IL- 6 after weight loss, $\Delta \mathrm{IL}-6$, was compared with the improvement in insulin sensitivity after weight loss, $\triangle \mathrm{HOMA}(\mathrm{A})$ or $\Delta$ insulin (B) in 19 obese subjects. HOMA was calculated as described in the Subjects and methods section. Bivariate correlation was assessed with Pearson correlation coefficient $\left(r_{p}\right)$. 
release of IL-8 from the adipose tissue to the circulation by measuring the arterio-venous difference of IL-8 over an adipose tissue depot. Another point of interest would be to investigate whether IL-8 has any effects on cellular insulin sensitivity. Weight loss in obese men was found to be associated with a decrement in the circulating levels of IL-6 and TNF- $\alpha$, but an increment in the circulating levels of IL-8. This increment was unexpected, but could be due to additional inflammatory changes associated with weight loss.

\section{Acknowledgements}

The technical assistance of Lenette Pedersen and Pia Hornbek is gratefully appreciated.

The study has been supported by The Novo Nordic Foundation, The Danish Medical Research Council and the Aarhus University-Novo Nordic Centre for Research in Growth and Regeneration. The low calorie formula diet GERLINÉA was donated by WASABRØD A/S; Skovlunde Denmark.

\section{References}

1 Kopelman PG. Obesity as a medical problem. Nature $2000 \mathbf{4 0 4}$ 635-643.

2 Kahn BB \& Flier JS. Obesity and insulin resistance. Journal of Clinical Investigation $2000 \mathbf{1 0 6} 473-481$.

3 Ravussin E \& Smith SR. Increased fat intake, impaired fat oxidation, and failure of fat cell proliferation result in ectopic fat storage, insulin resistance, and type 2 diabetes mellitus. Annals of the New York Academy of Sciences 2002967 363-378.

4 Mohamed-Ali V, Goodrick S, Rawesh A, Katz DR, Miles JM, Yudkin JS et al. Subcutaneous adipose tissue releases interleukin-6, but not tumor necrosis factor-alpha, in vivo. Journal of Clinical Endocrinology and Metabolism 199782 4196-4200.

5 Hotamisligil GS \& Spiegelman BM. Tumor necrosis factor alpha: a key component of the obesity-diabetes link. Diabetes $1994 \mathbf{4 3}$ $1271-1278$.

6 Bruun JM, Pedersen SB \& Richelsen B. Regulation of interleukin 8 production and gene expression in human adipose tissue in vitro. Journal of Clinical Endocrinology and Metabolism $2001 \mathbf{8 6}$ $1267-1273$.

7 Lonnqvist F, Arner P, Nordfors L \& Schalling M. Overexpression of the obese $(\mathrm{ob})$ gene in adipose tissue of human obese subjects [see comments]. Nature Medicine 19951 950-953.

8 Alessi MC, Peiretti F, Morange P, Henry M, Nalbone G \& Juhan-Vague I. Production of plasminogen activator inhibitor 1 by human adipose tissue: possible link between visceral fat accumulation and vascular disease. Diabetes 199746 860-867.

9 Maeda K, Okubo K, Shimomura I, Funahashi T, Matsuzawa Y \& Matsubara K. cDNA cloning and expression of a novel adipose specific collagen-like factor, apM1 (AdiPose Most abundant Gene transcript 1). Biochemical and Biophysical Research Communications $1996221286-289$.

10 Dandona P, Weinstock R, Thusu K, Abdel-Rahman E, Aljada A \& Wadden T. Tumor necrosis factor-alpha in sera of obese patients: fall with weight loss. Journal of Clinical Endocrinology and Metabolism $1998 \mathbf{8 3} 2907-2910$.

11 Bastard JP, Jardel C, Bruckert E, Blondy P, Capeau J, Laville M et al. Elevated levels of interleukin 6 are reduced in serum and subcutaneous adipose tissue of obese women after weight loss. Journal of Clinical Endocrinology and Metabolism 2000853338 -3342.
12 Lang CH, Dobrescu C \& Bagby GJ. Tumor necrosis factor impairs insulin action on peripheral glucose disposal and hepatic glucose output. Endocrinology $199213043-52$.

13 Hotamisligil GS, Shargill NS \& Spiegelman BM. Adipose expression of tumor necrosis factor-alpha: direct role in obesitylinked insulin resistance. Science $199325987-91$.

14 Hauner H, Petruschke T, Russ M, Rohrig K \& Eckel J. Effects of tumour necrosis factor alpha (TNF alpha) on glucose transport and lipid metabolism of newly differentiated human fat cells in cell culture. Diabetologia 199538 764-771.

15 Barnes PJ \& Karin M. Nuclear factor-kappaB: a pivotal transcription factor in chronic inflammatory diseases. New England Journal of Medicine 1997336 1066-1071.

16 Kern PA, Ranganathan S, Li C, Wood L \& Ranganathan G. Adipose tissue tumor necrosis factor and interleukin-6 expression in human obesity and insulin resistance. American Journal of Physiology, Endocrinology and Metabolism 2001280 E745-E751.

17 Ofei F, Hurel S, Newkirk J, Sopwith M \& Taylor R. Effects of an engineered human anti-TNF-alpha antibody (CDP571) on insulin sensitivity and glycemic control in patients with NIDDM. Diabetes $199645881-885$.

18 Fried SK, Bunkin DA \& Greenberg AS. Omental and subcutaneous adipose tissues of obese subjects release interleukin-6: depot difference and regulation by glucocorticoid. Journal of Clinical Endocrinology and Metabolism $1998 \mathbf{8 3}$ 847-850.

19 Ridker PM, Rifai N, Stampfer MJ \& Hennekens CH. Plasma concentration of interleukin- 6 and the risk of future myocardial infarction among apparently healthy men. Circulation 2000 $1011767-1772$.

20 Vgontzas AN, Papanicolaou DA, Bixler EO, Kales A, Tyson K \& Chrousos GP. Elevation of plasma cytokines in disorders of excessive daytime sleepiness: role of sleep disturbance and obesity [see comments]. Journal of Clinical Endocrinology and Metabolism 1997 $821313-1316$.

21 Gerhardt CC, Romero IA, Cancello R, Camoin L \& Strosberg AD. Chemokines control fat accumulation and leptin secretion by cultured human adipocytes. Molecular and Cellular Endocrinology $200117581-92$.

22 Liu Y, Hulten LM \& Wiklund O. Macrophages isolated from human atherosclerotic plaques produce IL-8, and oxysterols may have a regulatory function for IL-8 production. Arteriosclerosis, Thrombosis, and Vascular Biology 199717 317-323.

23 Moreau M, Brocheriou I, Petit L, Ninio E, Chapman MJ \& Rouis M. Interleukin-8 mediates downregulation of tissue inhibitor of metalloproteinase-1 expression in cholesterol-loaded human macrophages: relevance to stability of atherosclerotic plaque. Circulation 199999 420-426.

24 Gerszten RE, Garcia-Zepeda EA, Lim YC, Yoshida M, Ding HA, Gimbrone MAJ et al. MCP-1 and IL- 8 trigger firm adhesion of monocytes to vascular endothelium under flow conditions. Nature $1999398718-723$.

25 Shin WS, Szuba A \& Rockson SG. The role of chemokines in human cardiovascular pathology: enhanced biological insights. Atherosclerosis $2002 \mathbf{1 6 0} 91-102$.

26 Zozulinska D, Majchrzak A, Sobieska M, Wiktorowicz K \& Wierusz-Wysocka B. Serum interleukin-8 level is increased in diabetic patients [letter]. Diabetologia 199942 117-118.

27 Tashiro K, Koyanagi I, Saitoh A, Shimizu A, Shike T, Ishiguro C et al. Urinary levels of monocyte chemoattractant protein-1 (MCP-1) and interleukin-8 (IL-8), and renal injuries in patients with type 2 diabetic nephropathy. Journal of Clinical Laboratory Analysis $2002161-4$.

28 Verdich C, Madsen JL, Toubro S, Buemann B, Holst JJ \& Astrup A. Effect of obesity and major weight reduction on gastric emptying. International Journal of Obesity and Related Metabolic Disorders $200024899-905$.

29 Verdich C, Toubro S, Buemann B, Holst JJ, Bulow J, Simonsen L et al. Leptin levels are associated with fat oxidation and dietaryinduced weight loss in obesity. Obesity Research $20019452-461$. 
30 Emoto M, Nishizawa Y, Maekawa K, Hiura Y, Kanda H, Kawagishi $\mathrm{T}$ et al. Homeostasis model assessment as a clinical index of insulin resistance in type 2 diabetic patients treated with sulfonylureas. Diabetes Care 199922 818-822.

31 Steppan CM \& Lazar MA. Resistin and obesity-associated insulin resistance. Trends in Endocrinology and Metabolism 200213 $18-23$.

32 Bruun JM, Pedersen SB, Kristensen K \& Richelsen B. Opposite regulation of interleukin- 8 and tumor necrosis factor-alpha by weight loss. Obesity Research 200210 499-506.

33 Kern PA, Saghizadeh M, Ong JM, Bosch RJ, Deem R \& Simsolo RB. The expression of tumor necrosis factor in human adipose tissue. Regulation by obesity, weight loss, and relationship to lipoprotein lipase. Journal of Clinical Investigation 199595 2111-2119.

34 Bastard JP, Maachi M, Van Nhieu JT, Jardel C, Bruckert E, Grimaldi A et al. Adipose tissue IL-6 content correlates with resistance to insulin activation of glucose uptake both in vivo and in vitro. Journal of Clinical Endocrinology and Metabolism $2002872084-2089$.

35 Reape TJ \& Groot PH. Chemokines and atherosclerosis. Atherosclerosis 1999147 213-225.

36 Baggiolini M, Loetscher P \& Moser B. Interleukin- 8 and the chemokine family. International Journal of Immunopharmacology 199517 103-108.

37 Baldwin AS. Series introduction: the transcription factor NFkappaB and human disease. Journal of Clinical Investigation 2001 $1073-6$.

38 Heilbronn LK, Noakes M \& Clifton PM. Energy restriction and weight loss on very-low-fat diets reduce C-reactive protein concentrations in obese, healthy women. Arteriosclerosis, Thrombosis, and Vascular Biology 200121 968-970.

39 Tchernof A, Nolan A, Sites CK, Ades PA \& Poehlman ET. Weight loss reduces $\mathrm{C}$-reactive protein levels in obese postmenopausal women. Circulation 2002105 564-569.

40 Imbeault P, Chevrier J, Dewailly E, Ayotte P, Despres JP, Tremblay A et al. Increase in plasma pollutant levels in response to weight loss in humans is related to in vitro subcutaneous adipocyte basal lipolysis. International Journal of Obesity and Related Metabolic Disorders 200125 1585-1591.

41 Hotamisligil GS, Arner P, Caro JF, Atkinson RL \& Spiegelman BM. Increased adipose tissue expression of tumor necrosis factor-alpha in human obesity and insulin resistance. Journal of Clinical Investigation $1995952409-2415$.

42 Gallistl S, Sudi KM, Aigner R \& Borkenstein M. Changes in serum interleukin- 6 concentrations in obese children and adolescents during a weight reduction program. International Journal of Obesity and Related Metabolic Disorders 200125 1640-1643.

43 Schreyer SA, Chua SCJ \& LeBoeuf RC. Obesity and diabetes in TNF-alpha receptor- deficient mice. Journal of Clinical Investigation $1998102402-411$.

44 Stephens JM, Butts MD \& Pekala PH. Regulation of transcription factor mRNA accumulation during 3T3-L1 preadipocyte differentiation by tumour necrosis factor-alpha. Journal of Molecular Endocrinology $1992961-72$.

Received 27 August 2002

Accepted 25 February 2003 